\title{
Rhabdophis tigrinus (Yamakagashi) Bites in Japan Over the Last 50 Years: A Retrospective Survey
}

\begin{abstract}
Toru Hifumi ${ }^{1 *}$, Atsushi Sakai ${ }^{2}$, Akihiko Yamamoto ${ }^{3}$, Kazunori Morokuma ${ }^{4,5}$, Norio Otani ${ }^{1}$, Motohide Takahashi ${ }^{4}$ and Manabu Ato ${ }^{6}$

${ }^{1}$ Department of Emergency and Critical Care Medicine, St. Luke's International Hospital, Tokyo, Japan, ${ }^{2}$ The Japan Snake Institute, Gunma, Japan, ${ }^{3}$ Management Department of Biosafety and Laboratory Animal, National Institute of Infectious Disease, Tokyo, Japan, ${ }^{4}$ Toxin and Biologicals Research Laboratory, Kumamato Health Science University, Kumamoto, Japan, ${ }^{5}$ Kikuchi Quality Control Department, KM Biologics Co., Ltd., Kumamoto, Japan, ${ }^{6}$ Leprosy Research Center, National Institute of Infectious Diseases, Tokyo, Japan
\end{abstract}

Introduction: Rhabdophis snakes, which include 27 species, are rear-fanged venomous snakes that are widely distributed from India to East Asia and Russia. Severe envenomation by $R$. tigrinus (Yamakagashi snake) in Japan and $R$. subminiatus in Southeast Asia has been reported. The epidemiology of $R$. tigrinus bites, such as geographical features, the incidence, and changes in the number of bites over time have not been comprehensively examined. Hence, we intended to clarify the epidemiological features of $R$. tigrinus bites through a careful review of scientific data over the last 50 years in Japan.

Reviewed by: University of Peradeniya, Sri Lank Yasuhiro Kuroda, Kagawa University, Japan Juan J. Calvete, Spanish National Research Council (CSIC), Spain

*Correspondence: Toru Hifumi hifumitoru@gmail.com

Specialty section:

This article was submitted to Disaster and Emergency Medicine,

a section of the journal

Frontiers in Public Health

Received: 14 September 2021 Accepted: 30 November 2021

Published: 10 January 2022

Citation:

Hifumi T, Sakai A, Yamamoto A, Morokuma K, Otani N, Takahashi M and Ato M (2022) Rhabdophis tigrinus (Yamakagashi) Bites in Japan Over the Last 50 Years: A Retrospective Survey.

Front. Public Health 9:775458.

doi: 10.3389/fpubh.2021.775458
Methods: Patient records of R. tigrinus bites between 1971 and 2020 at the Japan Snake Institute were examined retrospectively. The following were ascertained: patient characteristics, clinical symptoms, laboratory data, treatment-related factors, and hospital mortality. These variables were compared in the antivenom and the without-antivenom groups.

Results: Over the 50-year study period, 43 R. tigrinus bites, including five fatal cases, were encountered. Severe cases of $R$. tigrinus bites have been treated with antivenom since 1985; however, fatalities occurred in 2006 and 2020. $R$. tigrinus bite cases have been well-distributed in the western part of Japan since 2000. The mortality rate in the antivenom group was significantly lower in the patient group that was not administered the antivenom ( 0 vs. $23.8 \%, p=0.048$ ).

Conclusion: This study clarified the epidemiology of $R$. tigrinus bites in Japan over a 50 -year period. Almost all severe cases of $R$. tigrinus bites have been treated with the antivenom in the current situation, and fatalities occurred in cases not treated with the antivenom. It is important to diagnose $R$. tigrinus bites in the early phase of the clinical course. The antivenom, the definitive treatment for $R$. tigrinus bites, is an unapproved drug. Hence, approval needs to be obtained for the drug.

Keywords: snake envenomation, antivenom, disseminated intravascular coagulation, neglected tropical disease, Yamakagashi 


\section{INTRODUCTION}

Snakes of genus Rhabdophis include 27 species of rear-fanged venomous snakes that are widely distributed from India to East Asia and Russia. Severe envenomation by $R$. tigrinus (Yamakagashi snake) in Japan and $R$. subminiatus in Southeast Asia have been reported (1-5). Their bites lead to venom-induced consumption coagulopathy (VICC), resulting in hemorrhage (6, 7 ). The experimental use of antivenom against $R$. tigrinus bites was first tested in 1985 on immunized rabbits (1). Currently, the antivenom against $R$. tigrinus bites is provided for use only in clinical research because it is an unapproved drug in Japan $(1,4,8)$. Our research group is currently working on the supply of antivenom as a serum therapy against $R$. tigrinus bites (9-13).

The clinical characteristics of $R$. tigrinus bites in Japan have been studied as part of a national survey from 2000 to 2013 (14), and its treatment (i.e., efficacy of $R$. tigrinus antivenom) has also been evaluated from 1973 to 2013 (15). However, the epidemiology of $R$. tigrinus bites, including the change of the geographical distribution and incidence over the time has not been well-studied.

In this study, we aimed to clarify the epidemiological features of $R$. tigrinus bites in Japan by retrospectively reviewing scientific data over the last 50 years.

\section{MATERIALS AND METHODS}

This study was approved by the Institutional Review Board, St. Luke's International Hospital, with approval number 21-R093.

\section{Patients and Setting}

In 1968, the Japan Snake Institute (JSI) was founded in the Gunma Prefecture to conduct research and provide enlightenment on snakes (15). This institute provides medical support to physicians handling patients with venomous snake bites where diagnosis is sometimes achieved based on patient history, laboratory analyses, and clinical symptoms. In this study, we conducted a retrospective review by collecting clinical data and all recorded cases of $R$. tigrinus bites at JSI from January 1, 1971, to December 31, 2020.

\section{Diagnosis of $\boldsymbol{R}$. tigrinus Bites}

The diagnosis of $R$. tigrinus bites was based on the patients' description of the snakes and the presence of VICC in patients with hypofibrinogenaemia.

\section{Data Collection}

Data on age, sex, date of injury (year), place of injury, clinical symptoms, laboratory analyses, treatment-related factors, and hospital mortality were recorded.

\section{Primary Data Analyses Statistical Analysis}

To compare the data pertaining to patient characteristics, treatment-related factors and outcomes between the antivenom patient group and the without-antivenom group, the MannWhitney $U$-test or the Chi square $\left(\chi^{2}\right)$ test was used.
TABLE 1 | Population characteristics of the patients.

\begin{tabular}{lc}
\hline Characteristics & All ( $\boldsymbol{n}=\mathbf{4 3})$ \\
\hline Age (years) & $37(12-57)$ \\
Sex, male & $42(97.7)$ \\
Clinical symptoms & \\
Nasal bleeding & $4(10.8)$ \\
Gum bleeding & $15(40.5)$ \\
Bleeding from the bite sites & $29(80.6)$ \\
Headache & $6(16.7)$ \\
Laboratory data & \\
Platelet counts $\left(\times 10^{4} / \mathrm{mm}^{3}\right)$ & $10.9(5.7-15.6)$ \\
Fibrinogen $(\mathrm{mg} / \mathrm{dL})$ & $35(20-50)$ \\
PT-INR & $4.4(2.3-7)$ \\
FDP ( $\mu$ g/mL) & $200(80.3-320)$ \\
Treatment & \\
PE & $4(10.8)$ \\
Outcome & \\
Mortality & $5(11.9)$ \\
\hline
\end{tabular}

Data are presented as median (interquartile, IQR) for continuous variables and $n$ (percentage) for categorical variables.

PT-INR, prothrombin time international ratio; FDP, fibrinogen degradation products; PE, plasma exchange.

Missing data: Age $=0$, Sex male $=0$, Nasal bleeding $=6$, Gum bleeding $=6$, Bleeding from the bite sites $=7$, Headache $=7$, Platelet counts $=19$, Fibrinogen $=19, P T-I N R=$ 23, $F D P=16, P E=6$, Mortality $=1$.

Furthermore, the Fisher exact test for $2 \times 2$ categorical variables was used when appropriate. $P$-values $<0.05$ were considered statistically significant. All analyses were completed using the JMP version 11 (SAS, Cary, North Carolina) software.

\section{RESULTS}

\section{Demographic and Clinical Characteristics of the Patients}

Table 1 summarizes the patient characteristics. Over the 50-year study period, $43 R$. tigrinus bite patients were recognized. The median age was 37 years, and $97.7 \%$ were men.

\section{Geographical Features of $\boldsymbol{R}$. tigrinus Bites}

$R$. tigrinus bite cases were found in almost all parts of Japan, except Hokkaido and Okinawa areas, and have been distributed in the western part of Japan since 2000. Fatalities have been limited to the western part, and specifically, there have been two fatalities in the Okayama Prefecture (Figures 1A-C).

\section{Trends in R. tigrinus Bites Over the Last $\mathbf{5 0}$ Years}

During the past 50 years, there have been several cases with $R$. tigrinus bites at intervals of 5 years. A fatal case tends to occur approximately once every 10 years (Figure $\mathbf{2 A}$ ). 
A All cases (From 1971 to 2020)

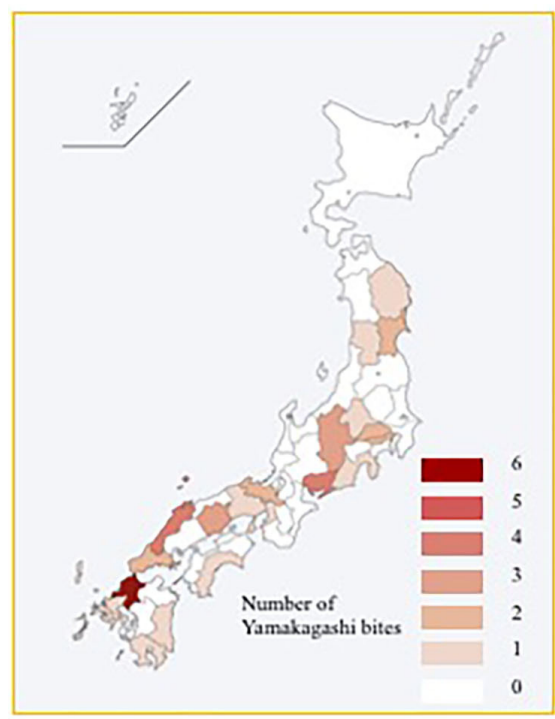

B Cases after 2000

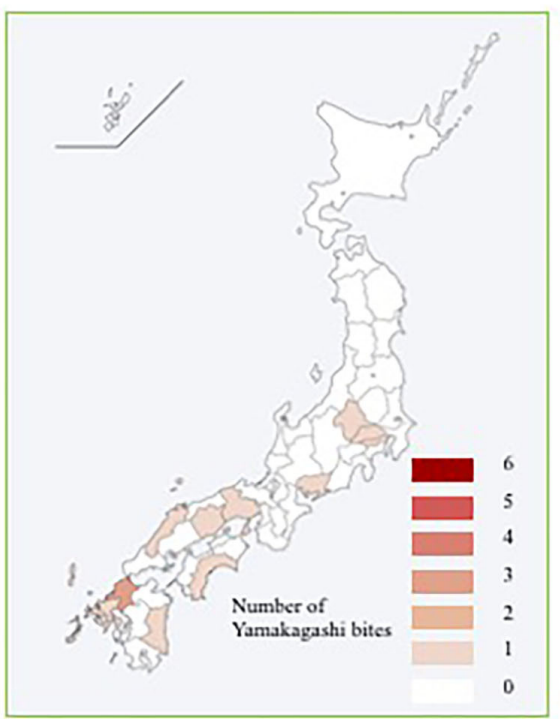

C Fatal cases

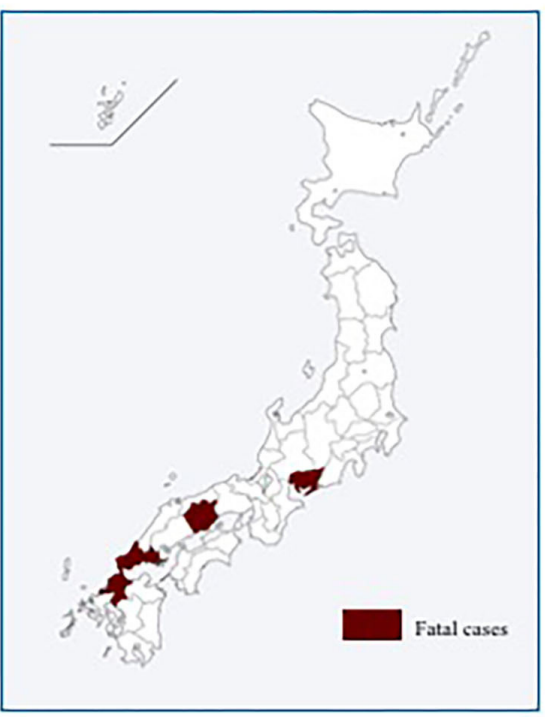

FIGURE 1 | Geographical features of R. tigrinus bites. (A) All cases (from 1971 to 2020). (B) Cases after 2000. (C) Fatal cases.

A

Number of Yamakagashi bites

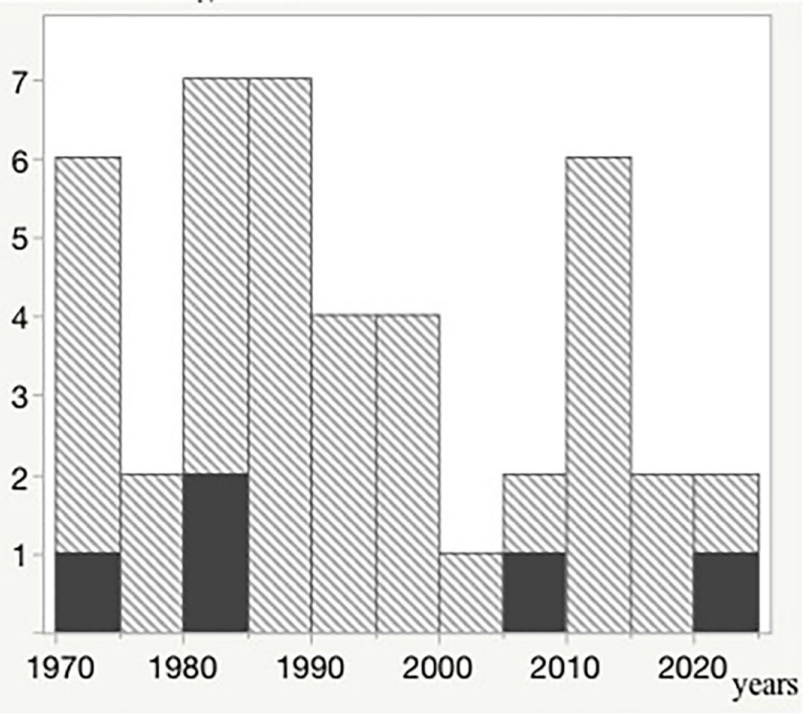

B

Number of Yamakagashi bites

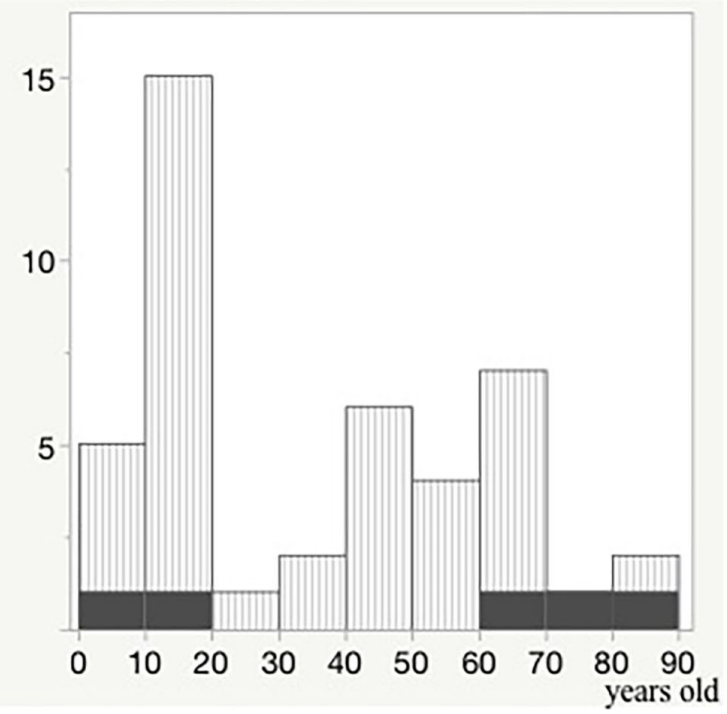

FIGURE 2 | Distribution of $R$. tigrinus bites in Japan. Trends in $R$. tigrinus bites over the last 50 years. The black regions indicate fatal cases. A single vertical bar indicates a 5-year period (1970-1974, 1975-1979, 1980-1984, 1985-1999, 2000-2004, 2005-2009, 2010-2014, 2015-2019, and 2020). Relationship between age and number of $R$. tigrinus bite cases. The black regions indicate fatal cases. A single vertical bar indicates a 10-year period (0-10, 11-20, 21-30, 31-40, 41-50, 51-60, 61-70, 71-80, and 81-90). (A,B) Number of Yamakagashi bites.

\section{Relationship Between Age and Number of R. tigrinus Bite Cases}

The relationship between age and the number of $R$. tigrinus bites is characteristic, with a clear peak in the teens. Fatal cases were observed in the elderly and children (Figure 2B).

\section{Trends in Patients Treated With Antivenom Over the Last 50 Years}

The first case of antivenom administration was in 1985, and almost all severe cases have been treated with the antivenom since then (Figure 3). 


\section{Number of Yamakagashi bites}

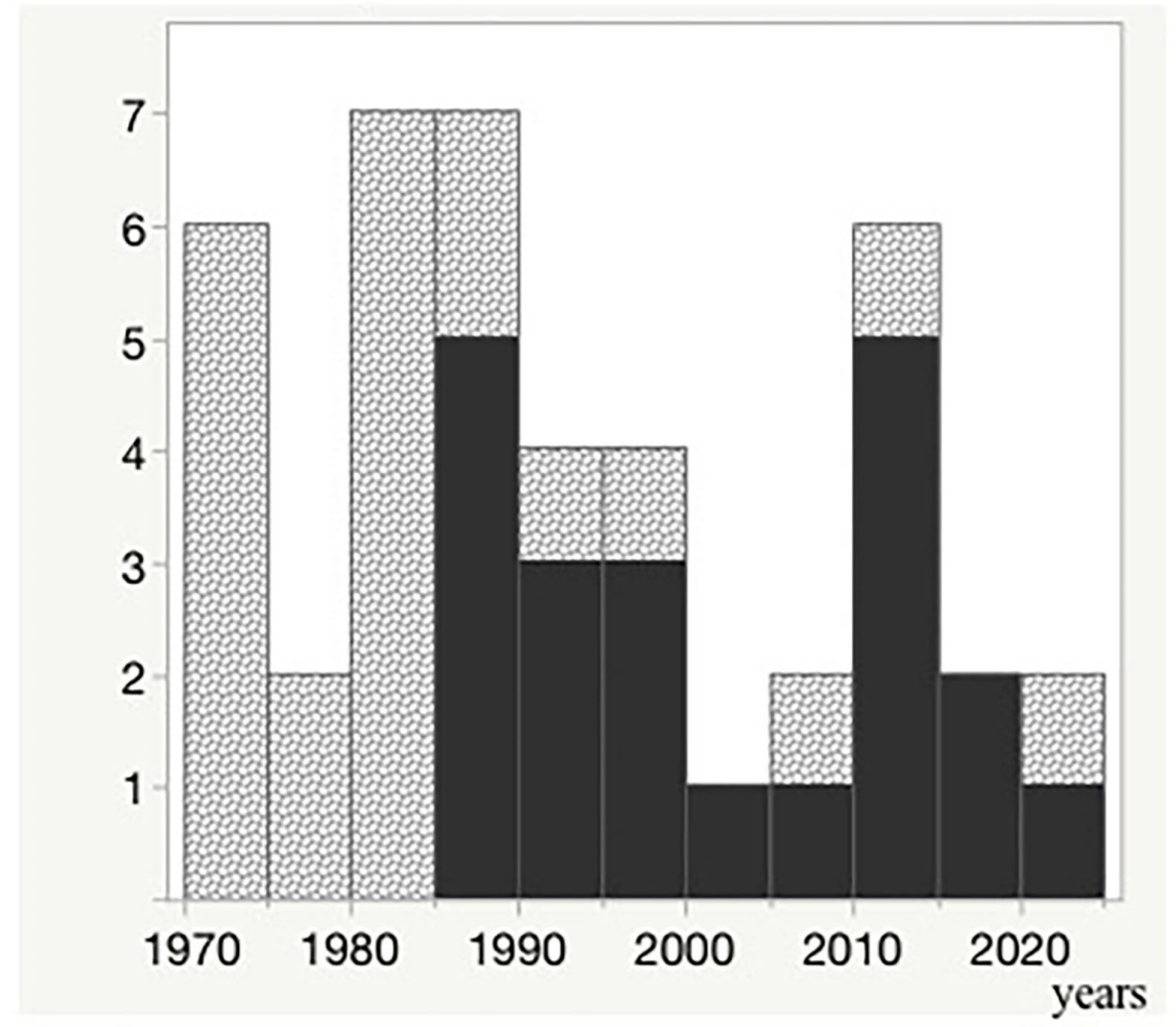

FIGURE 3 | Trends in patients treated with the antivenom over the last 50 years. The black regions indicate the antivenom administrated cases. A single vertical bar indicates a 5-year period (1970-1974, 1975-1979, 1980-1984, 1985-1999, 2000-2004, 2005-2009, 2010-2014, 2015-2019, and 2020). Number of Yamakagashi bites.

\section{Comparison of Clinical Characteristics Between the Antivenom and Without-Antivenom Patient Groups}

Table 2 presents the clinical features observed in the antivenom and without-antivenom groups. No significant differences were observed in the baseline characteristics and results of laboratory analyses between the two groups. The mortality rate in the antivenom group was significantly lower in the patient group that was not administered the antivenom ( 0 vs. $23.8 \%, p=0.048$ ).

\section{Details of Fatal Cases}

Details of fatalities are provided in Table 3. There have been two deaths since 2000 after the development of the antivenom. Our research group obtained the relevant clinical information after death or brain death in the two fatal cases. None of the fatal cases were treated with $R$. tigrinus antivenom. Cerebral hemorrhage was observed in least three out of five cases.

\section{DISCUSSION}

Over the 50-year study period, 43 cases of $R$. tigrinus bites, including five fatalities, were identified. Patients with $R$. tigrinus bites have been treated with the antivenom since 1985, and fatalities occurred in 2006 and 2020 in patients who were not treated with the antivenom.

Our survey showed that $R$. tigrinus bite cases have been welldistributed in the western part of Japan since 2000. Fatalities have also been limited to the western part. This finding is similar to the cases of pit viper bites reported previously $(9,10)$ and could be attributed to the short activity period due to the long winter experienced in the Tohoku and Hokuriku regions. Although the number of $R$. tigrinus cases is uncertain, it is believed that its density is less in the Tohoku and Hokuriku regions than in the western part of Japan mainly due to the varying climatic situations. The density of frogs, which are their bait, is also less in these regions than in western Japan, which affects the snake population.

The population of $R$. tigrinus is getting smaller (1). However, the number of $R$. tigrinus bites has remained almost constant. This discrepancy may be because many children, especially those who intentionally play with snakes, are bitten repeatedly, which allows the venom to enter the body and result in toxic bites (16).

Since the development of the antivenom for $R$. tigrinus bites in 1985, the number of fatalities has been reduced owing to the aggressive administration of the antivenom. However, 
TABLE 2 | Comparison of clinical characteristics between the antivenom and without-antivenom patient groups.

\begin{tabular}{|c|c|c|c|}
\hline Characteristics & Antivenom group $(n=21)$ & Without-antivenom group $(n=22)$ & $P$ \\
\hline Age (years) & $20(11-51)$ & $42(12-61)$ & 0.451 \\
\hline Sex, male & $20(95.2)$ & $22(100)$ & 0.488 \\
\hline \multicolumn{4}{|l|}{ Clinical symptoms } \\
\hline Nasal bleeding & $1(4.8)$ & $3(18.8)$ & 0.300 \\
\hline Gum bleeding & $8(38.1)$ & 7 (43.8) & 0.749 \\
\hline Bleeding from the bite sites & $17(85.0)$ & $12(75.0)$ & 0.675 \\
\hline Headache & $3(15.0)$ & $3(18.8)$ & 1.00 \\
\hline \multicolumn{4}{|l|}{ Laboratory data } \\
\hline Platelet counts $\left(\times 10^{4} / \mathrm{mm}^{3}\right)$ & $12.5(7.3-17.3)$ & $9.5(2.9-12.2)$ & 0.213 \\
\hline Fibrinogen (mg/dL) & $35(28-50)$ & $33(10-52)$ & 0.532 \\
\hline PT-INR & $5.8(2.8-7)$ & $2.6(2-5.5)$ & 0.094 \\
\hline FDP $(\mu \mathrm{g} / \mathrm{mL})$ & $262(173-397)$ & $160(70-284)$ & 0.070 \\
\hline \multicolumn{4}{|l|}{ Treatment } \\
\hline PE & $1(4.8)$ & 3(18.8) & 0.296 \\
\hline \multicolumn{4}{|l|}{ Outcome } \\
\hline Mortality & $0(0.0)$ & 5 (23.8) & 0.048 \\
\hline
\end{tabular}

Data are presented as median (interquartile, IQR) for continuous variables and n (percentage) for categorical variables.

PT-INR, prothrombin time international ratio; FDP, fibrinogen degradation products; PE, plasma exchange.

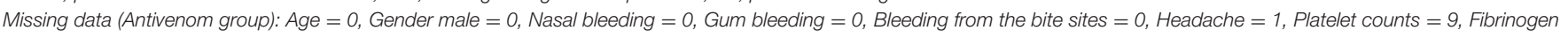
$=4, P T-I N R=8, F D P=4, P E=0$, Mortality $=0$.

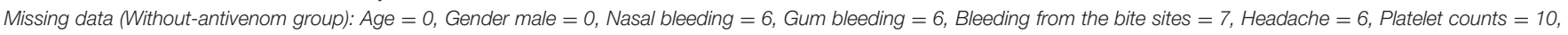
Fibrinogen $=15, P T-I N R=15, F D P=12, P E=6$, Mortality $=1$.

TABLE 3 | Clinical characteristics of fatal cases among R. tigrinus bite patients in Japan (1971-2020).

\begin{tabular}{|c|c|c|c|c|c|c|c|c|c|c|c|c|c|c|c|}
\hline \multicolumn{5}{|c|}{ Characteristics } & \multicolumn{4}{|c|}{ Clinical symptoms } & \multicolumn{4}{|c|}{ Laboratory data } & \multirow{2}{*}{$\frac{\text { Treatment }}{\text { Antivenom }}$} & \multicolumn{2}{|c|}{ Outcome } \\
\hline Case & Year & Area & Age & Sex & $\begin{array}{c}\text { Nasal } \\
\text { bleeding }\end{array}$ & $\begin{array}{c}\text { Gum } \\
\text { bleeding }\end{array}$ & $\begin{array}{l}\text { Bleeding } \\
\text { from the } \\
\text { bite sites }\end{array}$ & Headache & $\begin{array}{c}\text { Platelet } \\
\text { counts } \\
\left(\times 10^{4} / \mathrm{mm}^{3}\right)\end{array}$ & $\begin{array}{l}\text { Fibrinogen } \\
\text { (mg/dL) }\end{array}$ & PT-INR & $\begin{array}{c}\text { FDP } \\
(\mu \mathrm{g} / \mathrm{mL})\end{array}$ & & $\begin{array}{c}\text { Hospital } \\
\text { stay }\end{array}$ & $\begin{array}{c}\text { Brain } \\
\text { bleeding }\end{array}$ \\
\hline 1 & 2020 & Okayama & 80 & $\mathrm{M}$ & 0 & 0 & 1 & 0 & 11 & 50 & 2.12 & $\mathrm{~N} / \mathrm{A}$ & 0 & 1 & 1 \\
\hline 2 & 2006 & Fukuoka & 75 & $\mathrm{M}$ & 0 & 0 & 1 & 0 & 1.8 & 50 & 2.62 & 271.5 & 0 & 6 & 1 \\
\hline 3 & 1984 & Aichi & 14 & $\mathrm{M}$ & 0 & 0 & 1 & 1 & 9 & 5 & $\mathrm{~N} / \mathrm{A}$ & 40 & 0 & 10 & 1 \\
\hline 4 & 1982 & Yamaguchi & 6 & $\mathrm{M}$ & 0 & 0 & 0 & 0 & $\mathrm{~N} / \mathrm{A}$ & $\mathrm{N} / \mathrm{A}$ & N/A & $\mathrm{N} / \mathrm{A}$ & 0 & 4 & $\mathrm{~N} / \mathrm{A}$ \\
\hline 5 & 1972 & Okayama & 61 & $\mathrm{M}$ & 0 & 1 & 1 & 1 & $\mathrm{~N} / \mathrm{A}$ & 20 & N/A & $\mathrm{N} / \mathrm{A}$ & 0 & 60 & $\mathrm{~N} / \mathrm{A}$ \\
\hline
\end{tabular}

PT-INR, prothrombin time international ratio; FDP, fibrinogen degradation products; DIC, disseminated intravascular coagulation; PE, plasma exchange; N/A, not available.

two fatalities occurred in elderly people, both of whom were confirmed to have died from complications related to $R$. tigrinus bites. No fatalities have been observed among patients treated with the antivenom, which suggests that it is important to diagnose $R$. tigrinus bites in patients with unexplained severe coagulopathy (17) in the early phase of the clinical course. Raising awareness not only in the departments of emergency and intensive care but also in the fields of pediatrics and neurosurgery is imperative.

This study clarified the epidemiology of $R$. tigrinus bites in Japan over a 50 -year period. The antivenom was experimentally manufactured by regional health laboratories; however, its sterility and safety were not guaranteed (1). The Ministry of Health, Labor and Welfare of Japan, launched a research group to evaluate the safety and efficacy of the antivenom and to collect information on R. tigrinus bites in 2013 (18). The antivenom is stocked in some institutions and supplied to the hospital under the direction of the principal investigator in this research. Clinical characteristics and details of treatment, including the adverse effects of the antivenom, are recorded for all cases and analyzed to ensure proper safety (14). Therefore, based on the 50-year data, we plan to negotiate with the relevant authorities to obtain approval for the drug. Furthermore, the R. tigrinus species is not only found in Japan but also in Asia, and it is necessary to use these data to educate people in China and other countries where it is considered a non-toxic bite.

We observed some limitations in this study. Ours was a retrospective study, and a small sample size was utilized. There is the possibility of a selection bias since the cases reported were limited to our center only. The consistency of the type of data collected data, and the accuracy of data varied over the 50-year period, particularly in case of the laboratory data varies for the 
period of 50 years. Furthermore, some cases may have remained undiagnosed or misdiagnosed due to the unusual symptoms associated with this rare snakebite.

\section{CONCLUSION}

Over the 50-year study period, 43 cases of $R$. tigrinus bites, including five fatal cases, were identified. Almost all severe cases of $R$. tigrinus bites have been treated with the antivenom in the current situation, and fatalities occurred in patients who were not treated with the antivenom. It is important to diagnose $R$. tigrinus bites in patients with unexplained severe coagulopathy in the early phase of the clinical course. The antivenom, the definitive treatment for $R$. tigrinus bites, is an unapproved drug. Hence, it is necessary to obtain approval for this drug.

\section{DATA AVAILABILITY STATEMENT}

The raw data supporting the conclusions of this article will be made available by the authors, without undue reservation.

\section{REFERENCES}

1. Morokuma K, Kobori N, Fukuda T, Uchida T, Sakai A, Toriba M, et al. Experimental manufacture of equine antivenom against yamakagashi (Rhabdophis tigrinus). Jpn J Infect Dis. (2011) 64:397-402.

2. World Health Organization. Available online at: https://apps.who.int/ bloodproducts/snakeantivenoms/database/

3. Komori Y, Hifumi T, Yamamoto A, Sakai A, Ato M, Sawabe K, et al. Comparative study of biological activities of venom from colubrid snakes Rhabdophis tigrinus (Yamakagashi) and Rhabdophis lateralis. Toxins. (2017) 9:373. doi: 10.3390/toxins9110373

4. Hifumi T, Yamamoto A, Ato M, Sawabe K, Morokuma K, Morine N, et al. Clinical serum therapy: benefits, cautions, and potential applications. Keio J Med. (2017) 66:57-64. doi: 10.2302/kjm.2016-0017-IR

5. Hifumi T, Sakai A, Kondo Y, Yamamoto A, Morine N, Ato M, et al. Venomous snake bites: clinical diagnosis and treatment. I Intensive Care. (2015) 3:16. doi: 10.1186/s40560-015-0081-8

6. Isbister GK. Procoagulant snake toxins: laboratory studies, diagnosis, and understanding snakebite coagulopathy. Semin Thromb Hemost. (2009) 35:93103. doi: 10.1055/s-0029-1214152

7. Isbister GK. Snakebite doesn't cause disseminated intravascular coagulation: coagulopathy and thrombotic microangiopathy in snake envenoming. Semin Thromb Hemost. (2010) 36:444-51. doi: 10.1055/s-0030-1254053

8. Morokuma K, Matsumura T, Yamamoto A, Sakai A, Hifumi T, Ato M, et al. Evaluation of the stability of Yamakagashi (Rhabdophis tigrinus) Equine Antivenom after 20 years storage. Trop Biomed. (2021) 38:1118. doi: 10.47665/tb.38.2.042

9. Hifumi T, Yamamoto A, Morokuma K, Okada I, Kiriu N, Ogasawara T, et al. Clinical efficacy of antivenom and cepharanthine for the treatment of Mamushi (Gloydius blomhoffii) bites in tertiary care centers in Japan. Jpn J Infect Dis. (2013) 66:26-31. doi: 10.7883/yoken.66.26

10. Hifumi T, Yamamoto A, Morokuma K, Ogasawara T, Kiriu N, Hasegawa E, et al. Surveillance of the clinical use of mamushi (Gloydius blomhoffii) antivenom in tertiary care centers in Japan. Jpn J Infect Dis. (2011) 64:373-6.

11. Hifumi T, Okazaki T, Manabe A, Hamaya H, Egawa S, Fujimi S, et al. A national survey examining recognition, demand for antivenom, and overall level of preparedness for redback spider bites in Japan. Acute Med Surg. (2016) 3:310-4. doi: 10.1002/ams2.189

12. Hifumi T, Taki H, Yamamoto A, Ato M, Koido Y, Kuroda Y, et al. Update of antivenom supply for redback spider bites in Japan. J Intensive Care. (2015) 3:7. doi: 10.1186/s40560-014-0070-3

\section{ETHICS STATEMENT}

The studies involving human participants were reviewed and approved by St. Luke's International Hospital. Written informed consent to participate in this study was provided by the participants' legal guardian/next of kin.

\section{AUTHOR CONTRIBUTIONS}

$\mathrm{TH}$ and AS was responsible for conception of the article and drafted and revised the manuscript. AY, KM, NO, MT, and MA revised the manuscript. All authors read and approved the final manuscript.

\section{FUNDING}

This work was supported by the Research Program on Emerging and Re-emerging Infectious Disease from the Japan Agency for Medical Research and Development (AMED) 20fk0108101.

13. Hifumi T, Fujimi S, Yamagishi T, Arai S, Sawabe K, Yamamoto A, et al. Clinical characteristics of redback spider bites. J Intensive Care. (2014) 2:62. doi: 10.1186/s40560-014-0062-3

14. Hifumi T, Sakai A, Yamamoto A, Murakawa M, Ato M, Shibayama $\mathrm{K}$, et al. Clinical characteristics of yamakagashi (Rhabdophis tigrinus) bites: a national survey in Japan, 2000-2013. J Intensive Care. (2014) 2:19. doi: 10.1186/2052-0492-2-19

15. Hifumi T, Sakai A, Yamamoto A, Murakawa M, Ato M, Shibayama K, et al. Effect of antivenom therapy of Rhabdophis tigrinus (Yamakagashi snake) bites. J Intensive Care. (2014) 2:44. doi: 10.1186/s40560-014-0044-5

16. Ichiki T, Kohda F, Hiramatsu T, Saiki R, Sakai A, Furue M, et al. Early pathology in venom-induced consumption coagulopathy by Rhabdophis tigrinus (Yamakagashi snake) envenomation. Clin Toxicol. (2019) 57:66871. doi: 10.1080/15563650.2018.1540045

17. Yamamoto A, Ito T, Hifumi T. Attempt to develop rat disseminated intravascular coagulation model using Yamakagashi (Rhabdophis tigrinus) venom injection. Toxins. (2021) 13:160. doi: 10.3390/toxins13020160

18. Ministry of Health Labour and Welfare. General Overview of Research Projects. (2013). Available online at: http://www.mhlw.go.jp/seisakunitsuite/bunya/ hokabunya/kenkyujigyou/hojokin-koubo-h25/gaiyo/19.html (accessed December 15, 2021).

Conflict of Interest: KM was employed by company KM Biologics Co., Ltd.

The remaining authors declare that the research was conducted in the absence of any commercial or financial relationships that could be construed as a potential conflict of interest.

Publisher's Note: All claims expressed in this article are solely those of the authors and do not necessarily represent those of their affiliated organizations, or those of the publisher, the editors and the reviewers. Any product that may be evaluated in this article, or claim that may be made by its manufacturer, is not guaranteed or endorsed by the publisher.

Copyright (c) 2022 Hifumi, Sakai, Yamamoto, Morokuma, Otani, Takahashi and Ato. This is an open-access article distributed under the terms of the Creative Commons Attribution License (CC BY). The use, distribution or reproduction in other forums is permitted, provided the original author(s) and the copyright owner(s) are credited and that the original publication in this journal is cited, in accordance with accepted academic practice. No use, distribution or reproduction is permitted which does not comply with these terms. 